\title{
The Effect of Simulations and Games on Learning Objectives in Tertiary Education: A Systematic Review
}

\author{
Stephanie de Smale ${ }^{(\bowtie)}$, Tom Overmans, Johan Jeuring, \\ and Liesbeth van de Grint \\ Utrecht University, Utrecht, The Netherlands \\ \{S. deSmale, J. F. A. Overmans, J. T. Jeuring, \\ E.J.M.vandeGrint\}@uu.n工
}

\begin{abstract}
The growing popularity of simulations and games invites the production of insights that help academic teachers to use simulations and games in their courses. This article clarifies positive conditions to use simulations and games in tertiary education. Based on a systematic review of literature we tentatively find a positive or neutral relationship between using simulations and games and achieving learning objectives. Also, we find three recurring conditions for successful use of simulations and games: the specificity of the game, the integration in the course, and the role of a guiding instructor. Finally, we express the strong need for a scientific framework to measure effectiveness of simulations and games.
\end{abstract}

\section{Introduction}

Simulations and games are widely used in a diverse range of academic courses. Their use largely depends on teachers' personal initiatives and experiences in courses rather than on grounded information about which simulations work in which courses and for which learning objectives. Because game-based learning is increasingly popular in academic education, there is a need to validate the use of digital simulations and games. This study evaluates the value of simulations and games for tertiary education.

We analyse the relationship between simulations and games in academic programs and the achievement of learning objectives. Furthermore, we highlight what academic teachers can learn from previous studies. In a systematic literature review, we analyzed 64 articles focusing on tertiary education, games, and learning objectives. We find a tentative positive or neutral relationship between using simulations and games and achieving learning objectives, and three recurring preconditions for successful use of simulations and games: the specificity of the game, the integration in the course, and the role of a guiding instructor. Lastly, we think there is a need for a framework to measure effectiveness of simulations and games. 


\section{Learning Objectives, Simulations, and Games}

\subsection{Learning Objectives}

An important part of studying the value of simulations and games in tertiary education is concerned with its relationship with learning objectives. Learning objectives or learning outcomes describe what knowledge and skills students need to acquire. Learning objectives are fundamental in the design and validation of education. There are several frameworks for classifying learning objectives. Most widely known is Bloom's taxonomy, revised in 2001 by Anderson \& Krathwohl [1]. The applicability of Bloom's model for studying simulations and games is disputed. A shortcoming of Bloom's taxonomy in the context of this study is that it does not account for interactions among learners. Academic discourse on games and learning frame games as technologies that engage students in deep learning [2-4]. Skills like collaboration, but also critical thinking and problem solving are crucial in achieving deep learning goals $[5,6]$. While games appear to be particularly useful to engage students in skills for deep learning, traditional theories such as Bloom's taxonomy do not take these higher order skills sufficiently into account.

Simulations and games are often about acquiring skills. As a result, we adopt the taxonomy of Romiszowski [7], which focuses on these learning objectives, and explicitly differentiates between knowledge and skills. The term 'knowledge' refers to "information stored in the learner's mind" which can be differentiated into four different levels: facts, procedures, concepts, and principles. Skills refer to 'actions (intellectual and physical) and reactions (to ideas, things, or people), which a person performs in a competent way' [7]. Interactive skills, dealing with others, are one of the four skills categories of Romiszowsky's taxonomy. The other three are cognitive, psychomotor, and reactive. Additionally, Romiszowski distinguishes between reproductive skills (applying procedures) and productive skills (applying principles and strategies). Examples of these skills will be given later on in this article. We focus on the ability of simulations and games to transfer different type of skills. Which games enhance which types of learning skills?

\subsection{Simulations and Games}

The lack of a clear definition of simulations and games may result in what some scholars refer to as 'terminological ambiguity' [8]. In recent years many managers, educators, and other practitioners have turned to the study of simulations and games in education [9-11]. Also in academia simulations and games in education are a hot topic [12-16]. Contemporary studies on games and education use a variety of definitions: education games, serious games [17, 18], digital game-based learning [9], or applied games [19]. Despite the lack of shared definitions and terminology, authors generally focus on games in non-leisure contexts. Defining simulations and games contributes to terminological coherency and reduces ambiguity [8]. Although any classification of simulations and games is debatable, definitions of different forms are important when discussing effectiveness in academic education. In this study, we combine theory from 
Narayanasamy et al. [20], Lean et al. [21] and Apperley [22] to classify different types of simulations and games.

Simulations historically refer to both management/business simulations, and computer simulations [8]. In general, simulations are models that express complex real-world systems. A simulation is used to analyze specific systems, develop mental models in learners, or research artificial environments [20]. A difference between games and simulations is intent: 'the intent of games and simulation games is to engage players in a fun and entertaining experience, while the intent of simulators is to train and develop the skills of its operators' [20]. Relevant for this study are two different types of simulations: training and modeling simulations. Firstly, a training simulation also simulates real-world processes by re-enacting a specific type of system or process in order to improve performance, and maximize efficiency of the user [20]. One example is FlightGear Flight Simulator (1997). Secondly, modeling simulations are simulations that model specific systems in order create and/or test model - such as weather simulations or car modeling. Because the categorization of simulations and games are often ambiguous and their framing is also discipline-specific, we stress that the proposed categorization should be considered as a continuum rather than as completely separate categories. In this specific review the focus is on tertiary education and simulations and games that are often used in academic programs (Fig. 1).

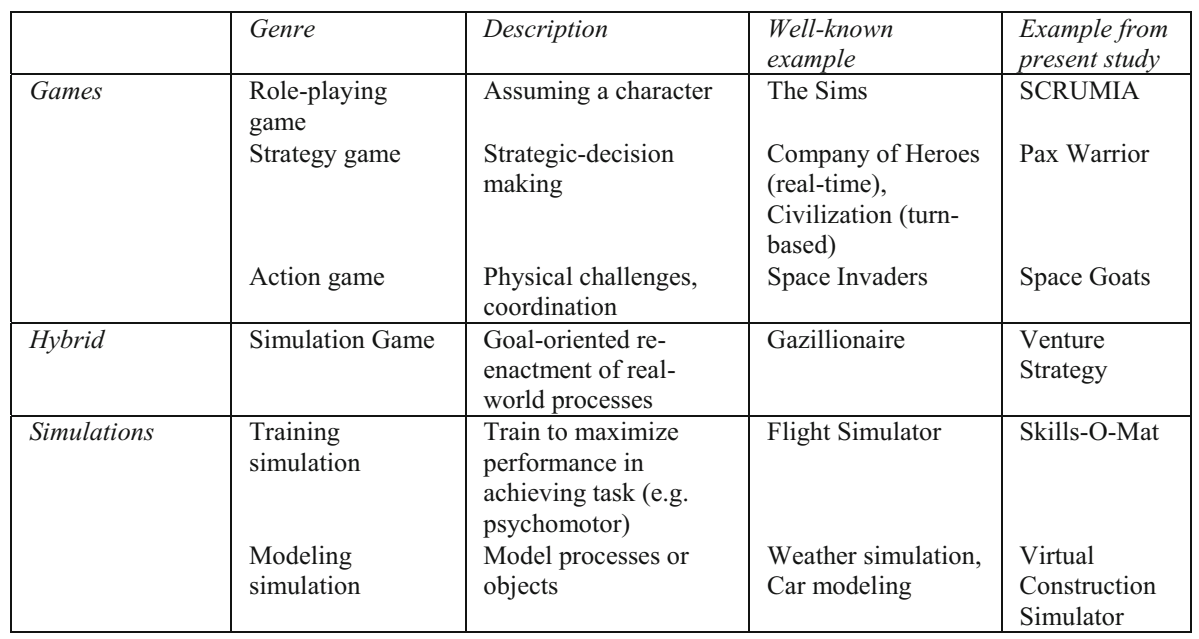

Fig. 1. Classification of games, simulation games, and simulations used in this review based on a combination of Narayanasamy et al. [20], Lean et al. [21], and Apperley [22].

Games, according to the traditional definition, are rule-bound systems, set in a defined space [23, 24]. Games are goal-oriented activities with clear in-game endings, as opposed to simulations, which may not have clear goal-oriented activities or end-states [20]. Simulation games have in-game goals, but successful completion of the game is not (necessarily) based on victory conditions. Firstly, role-playing games are games in which characters assume the role of a character or take control of an avatar in 
a fictional setting [22]. These games can be single, or multi-player, depending on the game's structure [21]. One well-known example is The Sims (Electronic Arts 2000). Secondly, strategy games are games in which player's decisions have a high significance in determining the outcome. These games are usually divided into real-time strategy games - such as Company of Heroes (Relic Entertainment 2006) - or turn-based strategy games - such as the Civilization series [22].

The third type of game is an action game, which focuses on physical challenges, such as reaction time or eye-hand coordination. A well-known game in this category is the classic Space Invaders (1978), but it should be noted that this type of game has many subgenres such as shooter- or fighting games. Besides simulations and games, there are simulation games, which is a hybrid form. While a simulation game is a subgenre of games, a simulation game does not have to be end-goal oriented and can be entertaining [20]. Simulation games are games that re-enact sports, flying, driving, but also real-world dynamics such as communities or governments [22]. Examples are games from the Lavamind series, such as Gazillionaire (2005). In this review, we found that these games appear both in a digital, physical, or a combination of digital and physical form. Therefore, in this classification all games, simulation games and simulations can be computer based, non-computer based or a hybrid of computer- and non-computer based.

\section{Research Method}

\subsection{Protocol and Selection}

A systematic review consists of five steps: (1) identification of research, (2) selection of primary studies, (3) study quality assessment, (4) data extraction \& monitoring, and (5) data synthesis [25]. Our main research objective is to uncover the value of simulations and games for tertiary education by exploring the relationships between their use in academic programs and the achievement of learning objectives.

In answering the research question, we produced a review protocol with several sub questions ${ }^{1}$, such as what type of simulations and games are used in higher education, and for what type of learning objectives games are useful?

For the selection of the primary research data, we conducted a comprehensive database search in SCOPUS. In SCOPUS, our query was: "serious gam*" or "simulation gam*". Within this query, we searched for articles related to education type, focusing on tertiary education; our query consisted of the search terms "university", "academic", or "tertiary" education. Second, since our research focused specifically on the relationship between games and learning objectives, the last part of the query consisted of a combination of the words "learning goals" or "learning objectives", or "learning outcomes".

\footnotetext{
${ }^{1}$ The research protocol can be obtained here: http://www.stephaniedesmale.n1/2015/10/22/researchprotocol/.
} 


\subsection{Assessment and Extraction}

The final literature review compared 64 articles. The initial dataset consisted of 728 articles. This dataset concerns journal articles with simulations, games or learning mentioned in its title and abstract. Starting with 728 articles a four stage-review process was carried out by a team of four researchers. In the first stage, articles were included or excluded from the review, using two criteria. Firstly, simulations or games and tertiary education had to be mentioned in the abstract, since the study focuses on the value simulations and games in tertiary education. Secondly, the articles had to focus on learning, i.e. on the achievement of learning objectives. If we were unsure if the article focused on higher education, the article was included in the shortlist for further examination. To provide a valid selection of articles for the shortlist, at least two researchers evaluated each title and abstract. The conflicting results were discussed by two researchers. After systematically reviewing 728 abstracts, a final shortlist of 93 articles remained; $14 \%$ of the initial dataset. In the second stage, four reviewers all read three different articles and one identical article. This was done to check the quality of the short list and to extract relevant topics for qualitative analysis. Eleven topics were extracted, and provided a solid base for a systematic analysis of the remaining articles. These topics concern, for instance, type of learning objectives, effect of simulations and games on learning objectives, type of research conducted, or academic discipline. In the third stage, all articles 93 articles were scrutinized and all topics were ranked in a database. In this stage, the set of 93 articles was reduced to 64, because 29 articles were excluded additionally. This was done for various reasons such as: the study did not focus on higher education, or the article was written in an inaccessible language. In the fourth and final stage several group meetings were organized to discuss the research findings, which formed the backbone of this article.

\section{Dataset Characteristics}

When analyzing our dataset, we found some interesting facts and figures. Most articles originated from the United States, The Netherlands, and the United Kingdom. Furthermore, we found that most simulations and games were used in the areas of computer science $(20,31 \%)$, engineering $(10,94 \%)$, or interdisciplinary courses $(10,94 \%)$. Most articles describe single case studies, in which a single game is analyzed and tested in a single educational setting. These studies usually examined the effect of a game by testing it for a specific amount of time (for instance, the duration of a course) and measuring before and after effects via questionnaires or interviews.

Most of the games studied are hybrid simulation games $(52,38 \%)$, role-playing games $(21,38 \%)$, or training/modeling simulations $(14,29 \%)$. The majority of these games is computer-based $(60,94 \%)$. One example of a studied simulation game is REALGAME, a business simulation played by students in the Business University of Turku, Finland [26]. In this study, 133 non-business majors participated in a business simulation course (2008 until 2012). Students' knowledge was evaluated in a pre- and post-game test in the form of a mental model. REALGAME is a continuously processed/clock-driven simulation game. In this example the simulation contributed to 
acquiring factual and conceptual knowledge of business. The objective for the simulation was to introduce novice students to business logic [26]. An example of a role-playing game is the Mastership Game, a collaborative role-playing game to teach pedagogy students didactic dilemmas in classroom situations [27]. There are players and observers, and players have to react to specific situations such as 'dealing with negative colleagues' [27]. An example of a training simulation is SCRUMIA, a paper-based role-playing game that teaches students SCRUM, a project management methodology. The learning objective of this study was a productive understanding of the SCRUM process. Focusing on practical knowledge transfer, students had to remember, understand, and apply procession knowledge [28].

\section{Value of Simulations and Games for Achieving Learning Objectives in Tertiary Education}

\subsection{Tentative Positive Effect on Learning Objectives}

We observe a tentative positive effect between simulations and games, and the achievement of learning objectives. Although all of the studies in our dataset somehow focus on learning objectives and simulations or games, only 29 reviewed articles explicitly refer to learning theories as conceptualized, for instance, by Bloom [1] or Romiszowski [7]. However, in labeling the declared learning goals in the articles, we found that simulations and games are deployed to develop a diverse range of cognitive and communicative skills: $37 \%$ related the simulation or game to productive cognitive skills (for example [27, 29-31], $16 \%$ procedural knowledge (for instance, [28, 32$34]$ ), and $12 \%$ productive interactive skills (such as [27, 30, 34]). Important to note is that most studies mentioned several learning objectives relevant to their research.

After studying the articles we remain reluctant about the validity of previous claims made about the clear and definite positive relationship between learning objectives and games. Out of 64 articles, only 29 studies explicitly studied the effects of simulations and games on learning objectives (for instance [27, 30, 35]). Despite the large diversity in studies, illustrated effects between the use of simulations and games and the achievement of learning objectives were always positive, or neutral. In the specific articles, results between simulations and games, and learning objectives were always positive (26 articles), or neutral (3 articles). One might consider this as a publication bias, where positive results are more likely to be published than negative results. Not a single study in our dataset suggested a negative relationship between the use of simulations and games and the achievement of learning objectives.

\subsection{Enabling and Constraining Factors}

Studying enabling factors in the effectiveness of simulations and games in academic education leads to the question: which conditions are of importance when using a simulation or game? First, the effectiveness of learning is strongly related to the role of the teacher/instructor/facilitator. Thirteen studies claimed the role of the instructor is 
vital for achieving learning objectives through simulations and games [26, 28-33, 3540]. Baalsrud Hauge et al. [33] show that the role of the teachers becomes more important when the emphasis on abstraction increases. In their meta-analysis, Wouters \& Van Oostendorp [41] identify that the role of instructional support enhances learning, especially when learning objectives involve (higher order) skills, and in discussing and selecting new information. There are different types of instructional support during a simulation or game: reflection, modeling, advice, collaboration, control, narrative elements, modality, feedback, and personalization [41]. These studies show that without instructional support, learning effect is constrained since players may use their capacity for ineffective activities such as focusing on irrelevant information.

For the effectiveness use of a game or simulation in an educational context, the specificity of the game and the desired learning objectives needs to be taken into account. To a certain extent, the game can be tailored to meet the desired learning goals. Eight studies found clearly defined learning objectives in using a specific simulation or game to be an important enabling factor [32, 35, 37, 42-46]. For example, Castronovo et al. [46] integrated the modeling simulation Virtual Construction Simulator 4 in a third year course 'Introduction to the Building Industry' and a fourth year course 'Building Construction Engineering' at Penn State University. In this case, the modeling simulation was specifically used in order to facilitate higher order thinking skills such as: evaluation, self-reflection, planning, determine appropriate construction methods. To accomplish this, the authors collaborated with course instructors to revise the existing set of learning objectives. This enhanced both the courses' and the simulation's objectives [46].

Lastly, the effect of simulations and games depends on course integration. Six studies found course integration an enabling factor in the effectiveness of a simulation or game [29, 30, 32, 33, 35, 47]. For instance, in Loughborough University the business game Venture Strategy was played by 70 senior-year students during the module 'Business Model'. It is a web-based team simulation where students start a company in the microcomputer industry [35]. This simulation deals with issues such as marketing, product development, accounting and finance. Using quantitative and qualitative analysis, subjects were asked to fill in a pre- and post-questionnaire and provide feedback during and after the courses. To improve the effectiveness of the module, some of the important enabling factors the authors suggest are: clear guidelines on coursework, realistic complexity, incentives for interaction, and face-to-face contact with course leader [35].

\subsection{The Need for a Univocal Framework}

Although we suggest a tentative positive relation between the use of simulations and games, and the achievement of learning objectives in tertiary education, we think it is too early to draw definite conclusions. Despite the growing attention for measuring effects of simulations and games on learning objectives, nearly all studies use self-developed evaluation instruments. These instruments vary from wide-ranging methods to very simple evaluations. This is issue is raised previously by several scholars [38, 41, 46, 48]. In addition to the large diversity of measurement tools, 
we find range of methods to classify learning objectives. As said, some studies explicitly use Bloom's taxonomy, whereas other studies mention obvious learning objectives. Using the studies in our dataset, we cannot draw definite conclusions concerning the effect of simulations and games on the achievement of learning objectives. Instead, we urge the need for an unambiguous framework to evaluate the effects. We suggest that this framework consists of (a) a clear classification of learning objectives which is recognizable for academic teachers, (b) a clear typology of simulations and games (in order to demonstrate which simulations and games might be helpful for achieving specific learning objectives) and (c) a sound scientific evaluation model using both quantitative and qualitative gathering techniques.

\section{Conclusion and Discussion}

We have studied the relationships between simulations and games and learning objectives in tertiary education. Our aim was to see if there are significant patterns between the use of simulations and games, and the achievement of learning objectives. Although the diversity of studies and experimental designs prohibit any hard results, three conclusions can be drawn from this study: we find a tentative positive effect between simulations and games and learning objectives, we suggest three recurring conditions for successful use of simulations and games, and we urge the need for a framework to measure the effectiveness of simulations and games.

This review has four theoretical and methodological limitations. Although we have tried to limit the chance, there might be a publication bias in our dataset. In performing a trans-disciplinary literature review, the articles differed in approach, methodology and situated knowledge.

The second limitation is the selection of data conducted in this study. In our own systematic review we used SCOPUS as our main database for extracting articles related to simulations and games in tertiary education. A limitation in this search strategy is the publication bias of relying on one database for our data.

A third possible limitation is the interpretation of learning objectives in the model of Romiszowski. We found Bloom's taxonomy inadequate for the study of higher order learning skills, which is why we used Romiszowski's learning theory. We interpreted the objectives mentioned in the articles and classified them using Romiszowski model. The classification depends on the reviewers' interpretation of the article. We have tried to improve the intercoder reliability by formulating a coding scheme, by reading and coding multiple articles team wise, and by discussing ambiguous learning objectives.

The fourth and last issue is concerned with the definition of simulations and games. We found that often a poor distinction was made between simulations and games. Generally it was not clear whether or not the articles were referring to games, which are goal-oriented, or simulations, which can also be open-ended. We elaborated on the differences in order to offer a frame of reference in an attempt to increase terminological coherence. However, in categorizing these simulations and games, we depended on information given in the article, which might have excluded valuable information to determine the type of game. In order to improve the intercoder reliability comparable steps were made (coding scheme, reading and coding team wise, discussing ambiguous types). 
We recommend two issues for further research. The first is concerned with a grounded understanding of types of learning objectives in studying the effects of games and learning. Few studies relate learning goals with theory on learning objectives, which is fundamental when studying the effects of games in academic education. This is closely related with knowledge on the specificity of, and between simulations and games, and their key characteristics. A second issue is concerned with developing and studying a univocal framework. Many studies were heterogeneous experiments, with varying evaluation and framework. A general framework for evaluating learning effects in using simulations and games is needed.

\section{References}

1. Krathwohl, D.: A revision of bloom's taxonomy: an overview. Theor. Pract. 41, 4 (2002)

2. Gee, J.P.: Learning and games. In: Salen, K. (ed.) The Ecology of Games: Connecting Youth, Games, and Learning, pp. 21-40. The MIT Press, Cambridge (2008). The John D. and Catherine T. MacArthur Foundation Series on Digital Media and Learning

3. Prensky, M.: Digital natives, digital immigrants part 1. Horizon 9(5), 1-6 (2001)

4. Egenfeldt-Nielsen, S., Smith, J.H., Tosca, S.P.: Understanding Video Games: The Essential Introduction. Routledge, London (2013)

5. Fullan, M., Langworthy, M.: Towards a New End: New Pedagogies for Deep Learning. Collaborative Impact, Seattle (2013)

6. Fullan, M., Langworthy, M.: A Rich Seam: How New Pedagogies Find Deep Learning. Pearson, London (2014)

7. Romiszowski, A.J.: Designing Instructional Systems. Kogan Page, London (1981)

8. Klabbers, J.H.G.: Terminological ambiguity game and simulation. Simul. Gaming 40(4), 446-463 (2009)

9. Prensky, M.: Digital game-based learning. Comput. Entertain. 1(1), 12-21 (2003)

10. Gibson, D., Aldrich, C., Prensky, M. (eds.): Games and Simulations in Online Learning: Research and Development Frameworks. IGI Global, Hershey (2006)

11. Aldrich, C.: The Complete Guide to Simulations and Serious Games: How the Most Valuable Content Will Be Created in the Age Beyond Gutenberg to Google, 1st edn. Pfeiffer, San Francisco (2009)

12. Squire, K.: Video games in education. Int. J. Intell. Simul. Gaming 2, 49-62 (2003)

13. Ritterfeld, U., Cody, M., Vorderer, P. (eds.): Serious Games. Mechanisms and Effects, 1st edn. Routledge, New York (2009)

14. Squire, K.: Video Games and Learning: Teaching and Participatory Culture in the Digital Age. Teachers College Press, New York (2011)

15. Khine, M.S. (ed.): Playful Teaching, Learning Games. New Tool for Digital Classrooms. Sense Publishers, Rotterdam, Boston (2011)

16. Shaffer, D.W., Gee, J.: The right kind of GATE, computer games and the future of assessment. In: Mayrath, M., Robinson, D., Clarke-Midura, J. (eds.) Technology-Based Assessments for 21st Century Skills, Theoretical and Practical Implications from Modern Research. Information Age Publishers, Charlotte (2012)

17. Sawyer, B., Rejeski, D.: Serious Games: Improving Public Policy Through Game-based Learning and Simulation. Woodrow Wilson International Center for Scholars, Washington (2002) 
18. Michael, D., Sande, C.: Serious Games: Games That Educate, Train, and Inform. Cengage Learning PTR, Boston (2005)

19. van Roessel, L., van Mastrigt-Ide, J.: Collaboration and team composition in applied game creation processes. In: DiGRA 2011, Proceedings of the 2011 DiGRA International Conference, Think Design Play, pp. 1-14 (2011)

20. Narayanasamy, W., Wong, K.K., Fung, C.C., Rai, S.: Distinguishing games and simulation games from simulators. Comput. Entertain. 4, 2 (2006)

21. Lean, J., Moizer, J., Towler, M., Abbey, C.: Simulations and games. use and barriers in higher education. Act. Learn. High Educ. 7(3), 227-242 (2006)

22. Apperley, T.H.: Genre and game studies: toward a critical approach to video game genres. Simul. Gaming 37(1), 6-23 (2009)

23. Huizinga, J.: Homo Ludens: Proeve Eener Bepaling Van Het Spel-Element Der Cultuur. University Press, Amsterdam (2008)

24. Caillois, R., Barash, M.: Man, Play, and Games. University of Illinois Press, Urbana (1961)

25. Kitchenham, B.: Procedures for performing systematic reviews. TR/SE-0401, Department of Computer Science, Keele University (2004)

26. Palmunen, L.-M., Pelto, E., Paalumäki, A., Lainema, T.: Formation of novice business students' mental models through simulation gaming. Simul. Gaming 44(6), 846-868 (2013)

27. Hummel, G.K., Geerts, W., Slootmaker, A., Kuipers, D., Westera, W.: Collaboration scripts for mastership skills. Online Game about Classroom Dilemmas in Teacher Education. Interactive Learning Environments 0.0, pp. 1-13. Taylor and Francis + NEJM, Web (2013)

28. von Wangenheim, C.G., Savi, R., Borgatto, A.F.: SCRUMIA. an educational game for teaching SCRUM in computing courses. J. Syst. Softw. 86(10), 2675-2687 (2013)

29. Günther, M., Kiesling, E., Stummer, C.: Game-based learning in technology management education. IEEE Educ. Eng. EDUCON 2010, 191-196 (2010)

30. Vos, L., Brennan, R.: Marketing simulation games: student and lecturer perspectives. Mark. Intell. Plann. 28(7), 882-897 (2010)

31. LeFlore, J.L., Anderson, M., Zielke, M.A., Thomas, P.E., Hardee, G., John, L.D.: Can a virtual patient trainer teach student nurses how to save lives, teaching nursing students about pediatric respiratory diseases, simulation in healthcare. J. Soc. Simul. Healthc. 7(1), 10-17 (2012)

32. Julien, F., Doutriaux, J., Couillard, J.: Teaching the production/operations management core course. integrating logistics planning activities. Prod. Oper. Manage. 7(2), 160-170 (1998)

33. Hauge, J.B., Bellotti, F., Nadolski, R., Berta, R., Carvalho, M.B.: Deploying serious games for management in higher education: lessons learned and good practices. EAI Endorsed Trans. Serious Games 1(3), 1-12 (2014)

34. Bayart, C., Bertezene, S., Vallat, D., Martin, J.: Serious games. leverage for knowledge management. TQM J. 26(3), 235-252 (2014)

35. Begum, M., Newman, R.: Evaluation of students' experiences of developing transferable skills and business skills using a business simulation game. In: FIE 2009, pp. 1-6 (2009)

36. Peters, V.A.M., Vissers, G.A.N.: A simple classification model for debriefing simulation games. Simul. Gaming 35(1), 70-84 (2004)

37. Bellotti, F., Berta, R., De Gloria, A., Lavagnino, E., Dagnino, F. M., Antonaci, A., Ott, M.: A gamified short course for promoting entrepreneurship among ICT engineering students. In: ICALT, pp. 31-32 (2013)

38. Mayer, I., Warmelink, H., Bekebrede, G.: Learning in a game-based virtual environment. a comparative evaluation in higher education. Eur. J. Eng. Educ. 38(1), 85-106 (2013). Taylor and Francis + NEJM

39. Adrian, A.: Borrowing experience: ASX share market game. Int. J. Innov. Learn. 16(1), 8196 (2014) 
40. Hämäläinen, R., Oksanen, K.: Collaborative 3D learning games for future learning: teachers' instructional practices to enhance shared knowledge construction among students. Technol. Pedagogy Educ. 23(1), 81-101 (2014)

41. Wouters, P., van Oostendorp, H.: A meta-analytic review of the role of instructional support in game-based learning. Comput. Educ. 60(1), 412-425 (2013)

42. Hannig, A., Lemos, M., Spreckelsen, C., Ohnesorge-Radtke, U., Rafai, N.: Skills-O-Mat. computer supported interactive motion- and game-based training in mixing alginate in dental education. J. Educ. Comput. Res. 48(3), 315-343 (2013)

43. Söbke, T.B.H.: Using the master copy-adding educational content to commercial video games, pp. 521-530 (2013)

44. Bellotti, F., Berta, R., De Gloria, A., Lavagnino, E., Antonaci, A., Dagnino, F., Ott, M., Romero, M., Usart, M., Mayer, I.S.: Serious games and the development of an entrepreneurial mindset in higher education engineering students. Entertainment Comput. 5(4), 357-366 (2014)

45. Boyle, E.A., MacArthur, E.W., Connolly, T.M., Hainey, T., Manea, M., Kärki, A., van Rosmalen, P.: A narrative literature review of games, animations and simulations to teach research methods and statistics. Comput. Educ. 74, 1-14 (2014)

46. Castronovo, F., Nikolic, D., Zappe, S.E., Leicht, R.M., Messner, J.I.: Enhancement of learning objectives in construction engineering education: a step toward simulation assessment. In: Construction Research Congress American Society of Civil Engineers, pp. 339-348 (2014)

47. Hauge, J.M.B., Pourabdollahian, B., Riedel, J.C.: The use of serious games in the education of engineers. In: Emmanouilidis, C., Taisch, M., Kiritsis, D. (eds.) Advances in Production Management Systems. IFIP AICT, vol. 397, pp. 622-629. Springer, Heidelberg (2013)

48. Freno, A., Trentin, E.: Applications. In: Freno, A., Trentin, E. (eds.) Hybrid Random Fields. ISRL, vol. 15, pp. 121-150. Springer, Heidelberg (2011) 